\title{
Annuloplasty as a method to prevent recurrent herniation of lumbar intervertebral discs
}

\author{
Taewon Choi, Ho Yong Choi, Dae Jean Jo \\ Department of Neurosurgery, Kyung Hee University Hospital at Gangdong, Seoul, Korea
}

Objective: Recurrent disc herniation occurs frequently after discectomy and is associated with annulus fibrosus defects. This study evaluated the effectiveness of annuloplasty in preventing recurrent intervertebral disc herniation following microscopic discectomy. Methods: We analyzed 102 patients (56 males, 46 females) who underwent discectomy between December 2019 and February 2021. Twenty-two patients received annuloplasty using sutures and 80 did not. Surgical and clinical outcomes and the herniation recurrence rate were compared between the groups.

Results: The mean age was significantly lower in the suture group than in the non-suture group $(54.55 \pm 10.12$ years vs. $60.60 \pm 12.20$ years; $P=0.021)$. There were no significant between-group differences in sex, body mass index, or length of follow-up. The surgical outcomes, such as operation time $(66.82 \pm 13.01$ minutes vs. $63.14 \pm 20.54$ minutes; $P=0.305)$ and estimated blood loss $(54.55 \pm 14.71$ $\mathrm{mL}$ vs. $59.77 \pm 19.59 \mathrm{~mL} ; \mathrm{P}=0.175)$, did not differ significantly between the groups. No significant between-group difference was found in the proportion of patients with lower extremity weakness preoperatively (63.6\% vs. 48.8\%; $P=0.155)$, and at $1(36.4 \%$ vs. $25.0 \% ; P=0.275)$ and 6 months $(13.6 \%$ vs. $11.3 \% ; P=0.707)$ postoperatively. There were no cases of recurrent herniation in the suture group, whereas the recurrence rate was $5.0 \%$ in the non-suture group.

Conclusion: Despite the non-statistically significant results, annuloplasty may serve as a simple method to prevent recurrent intervertebral disc herniation.

Keywords: Annuloplasty; Annular suture; Intervertebral disc herniation; Lumbar discectomy; Simple sutures

\section{Introduction}

Among patients with herniation of the intervertebral disc (HIVD), surgical treatment is recommended for patients with failure of conservative treatment or severe muscle weakness [1,2]. During surgical treatment, the herniated disc is removed to relieve the compressed cauda equina or nerve roots. Although surgical treatment is performed successfully, the risk of recurrence is reported to be up to $15 \%[3-5]$.

Received: August 27, 2021

Revised: September 23, 2021

Accepted: October 5, 2021

Corresponding Author: Ho Yong Choi, MD, PhD

Department of Neurosurgery, Kyung Hee University Hospital at Gangdong, 892 Dongnam-ro, Gangdong-gu, Seoul 05278, Korea

Tel: +82-2-440-8402; Fax: +82-2-440-8402;

E-mail: heoryong83@hanmail.net
During the surgical removal of HIVDs, annular defects inevitably occur, and are associated with recurrent herniation. To prevent annular defects associated with discectomy, annular repair is performed using an annular closure device or annuloplasty [6-11]. However, to the best of our knowledge, there are few studies in which annuloplasty was performed to prevent recurrent herniation in a clinical setting. The purpose of this study was to evaluate the effectiveness of annuloplasty in preventing recurrent herniation following microscopic discectomy.

\section{Material and Method}

\section{Study design}

We evaluated a total of 102 patients (56 males, 46 females) who underwent discectomy at a single academic institution between December 2019 and February 2021. Discectomy was performed using conventional microscopy. Patients with no improvement in 
symptoms despite conservative management for $>6$ weeks, or those with lower extremity weakness (defined as motor grade of 3 or lower) were selected for surgery. Annuloplasty was performed by placing one or 2 simple sutures using non-absorbable silk at the annular opening depending on the surgeon's preference. According to the performance of annuloplasty, 22 and 80 patients were classified into the suture and non-suture groups, respectively. Outpatient follow-up was performed at 1 and 6 months after discharge. Data including age, sex, body mass index, duration of symptoms, follow-up period, operation time, estimated blood loss (EBL), and length of hospital stay, were collected from the medical records and analyzed. Pre- and postoperative pain was assessed using the visual analogue scale (VAS). Recurrent HIVD was defined as the aggravation of preoperative symptoms confirmed by radiographic studies. Statistical analysis was performed using IBM SPSS Statistics ver. 26.0 (IBM, Corp., Armonk, NY, USA).

\section{Surgical procedure}

Discectomy was performed in the same way by 2 neurosurgeons, and all surgeries were performed under general anesthesia. The patient's position was prone, and the level was verified using the $\mathrm{C}$-arm. Discectomy was performed using a unilateral approach. After laminectomy, the prolapsed intervertebral disc was dissected and removed through the opening in the annulus. After confirming that the nerve root was decompressed, the annular opening was repaired using a simple suture with Mersilk 5-0 (Ethicon Inc., Raritan, NJ, USA) (Fig. 1).

\section{Results}

\section{Patients' demographics}

The demographic data are summarized in Table 1 . The mean age of the entire cohort was $59.37 \pm 12.01$ years; it was significantly lower in suture group than in non-suture group $(54.55 \pm 10.12$ years vs. $60.60 \pm 12.20$ years; $\mathrm{P}=0.021$ ). There were no significant differences in sex, body mass index and length of follow-up between the groups. Also, comorbidities and smoking status did not differ between the groups. The mean duration of symptoms was significantly longer in suture group than in the non-suture group ( $6.57 \pm 7.02$ months vs. $3.09 \pm 4.46$ months; $\mathrm{P}=0.036)$. Surgery was performed on patients with L4/5 and L5/S1 disc herniation, and the surgical level did not differ between the groups.

\section{Surgical and clinical outcomes}

Surgical and clinical outcomes are summarized in Table 2. The surgical outcomes, such as in operation time $(66.82 \pm 13.01 \mathrm{~min}-$ utes vs. $63.14 \pm 20.54$ minutes; $\mathrm{P}=0.305)$ and $\mathrm{EBL}(54.55 \pm$ $14.71 \mathrm{~mL}$ vs. $59.77 \pm 19.59 \mathrm{~mL} ; \mathrm{P}=0.175$ ), did not differ between the groups. The length of hospital stay was significantly lower in the suture group ( $7.91 \pm 0.92$ days), than in the non-suture group (11.35 \pm 4.10 days; $\mathrm{P}=0.002$ ).
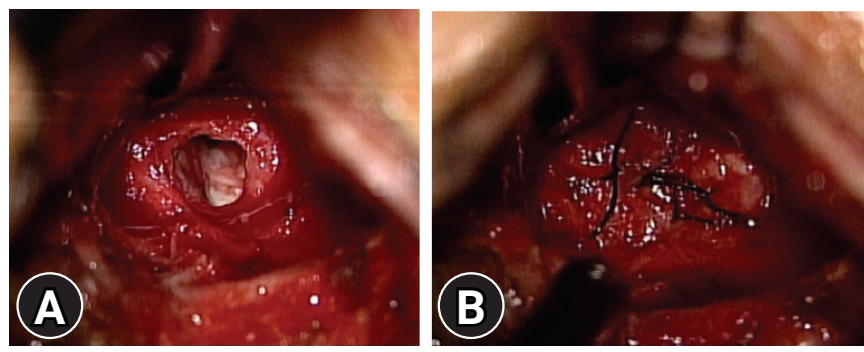

Fig. 1. (A) Photograph of an annular defect following microscopic discectomy. (B) Photograph of direct annular repair using simple sutures. Written informed consent was obtained for publication of this case report and accompanying images.

Table 1. Baseline characteristics of patients who underwent discectomy

\begin{tabular}{|c|c|c|c|}
\hline Characteristic & Suture group $(n=22)$ & Non-suture group $(n=80)$ & P-value \\
\hline Sex (male:female) & $8: 14$ & $48: 32$ & $0.055^{b)}$ \\
\hline Age (yr) & $54.55 \pm 10.12$ & $60.60 \pm 12.20$ & $0.021^{a) *}$ \\
\hline Body mass index $\left(\mathrm{kg} / \mathrm{m}^{2}\right)$ & $25.26 \pm 5.47$ & $25.96 \pm 3.16$ & $0.744^{a)}$ \\
\hline Hypertension & $7(31.8)$ & $38(47.5)$ & $0.294^{b)}$ \\
\hline Diabetes mellitus & $5(22.7)$ & 39 (48.8) & $0.054^{b)}$ \\
\hline Smoking & $5(22.7)$ & $38(47.5)$ & $0.067^{b)}$ \\
\hline Symptom duration (mo) & $6.57 \pm 7.02$ & $3.09 \pm 4.46$ & $0.036^{\mathrm{a}) *}$ \\
\hline Follow-up period (mo) & $3.45 \pm 2.37$ & $3.63 \pm 3.35$ & $0.820^{\mathrm{a})}$ \\
\hline Level & & & $0.132^{b)}$ \\
\hline L4-L5 & $18(81.8)$ & $54(67.5)$ & \\
\hline L5-S1 & $4(18.2)$ & $26(32.5)$ & \\
\hline
\end{tabular}

Values are presented as mean \pm standard deviation or number (\%).

a) Independent t-test, ${ }^{\text {b) }}$ chi-square test.

${ }^{*} \mathrm{P}<0.05$, statistically significant differences. 
Table 2. Surgical and clinical outcomes following discectomy

\begin{tabular}{|c|c|c|c|}
\hline Variable & Suture group $(n=22)$ & Non-suture group $(n=80)$ & P-value \\
\hline Operation time (min) & $66.82 \pm 13.01$ & $63.14 \pm 20.54$ & $0.305^{\mathrm{a})}$ \\
\hline Estimated blood loss (mL) & $54.55 \pm 14.71$ & $59.77 \pm 19.59$ & $0.175^{\mathrm{a})}$ \\
\hline Length of hospital stay (day) & $7.91 \pm 0.92$ & $11.35 \pm 4.10$ & $0.002^{\mathrm{a}) *}$ \\
\hline \multicolumn{4}{|l|}{ Weakness } \\
\hline Preoperative & $14(63.6)$ & 39 (48.8) & $0.155^{b)}$ \\
\hline Postoperative (1 mo) & $8(36.4)$ & $20(25.0)$ & $0.275^{\mathrm{b})}$ \\
\hline Postoperative (6 mo) & $3(13.6)$ & $9(11.3)$ & $0.707^{b)}$ \\
\hline \multicolumn{4}{|l|}{ Visual analogue scale } \\
\hline Preoperative & $7.00 \pm 1.16$ & $7.37 \pm 1.27$ & $0.213^{\mathrm{a})}$ \\
\hline Postoperative (1 mo) & $2.27 \pm 0.94$ & $2.50 \pm 1.33$ & $0.359^{\mathrm{a})}$ \\
\hline Postoperative (6 mo) & $0.36 \pm 0.49$ & $0.74 \pm 0.77$ & $0.006^{a) *}$ \\
\hline Recurrence (n/total) & $0 / 22(0)$ & $4 / 80(5.0)$ & $0.580^{c)}$ \\
\hline
\end{tabular}

Values are presented as mean \pm standard deviation or number (\%). Weakness was defined as a motor grade of 3 or lower.

${ }^{\text {a) }}$ Independent t-test, ${ }^{b)}$ Fisher exact test, ${ }^{\text {c) }}$ chi-square test.

${ }^{*} \mathrm{P}<0.05$, statistically significant differences.

Regarding neurological deficits, the proportion of patients with lower extremity weakness preoperatively (63.6\% vs. $48.8 \%$; $\mathrm{P}=0.155)$, and at 1 month $(36.4 \%$ vs. $25.0 \% ; \mathrm{P}=0.275)$ and 6 months ( $13.6 \%$ vs. $11.3 \%$; $\mathrm{P}=0.707)$ postoperatively did not differ significantly between the groups.

The preoperative VAS did not differ between the groups ( $7.00 \pm 1.16$ vs. $7.37 \pm 1.27 ; \mathrm{P}=0.213$ ); however, the intensity of pain was significantly lower in the suture group $(0.36 \pm 0.49)$, compared to that in the non-suture group $(0.74 \pm 0.77 ; \mathrm{P}=0.006)$ at 6 months postoperatively. Four patients $(5.0 \%)$ in the non-suture group required revision surgery due to recurrent HIVD, whereas no patient suffered from recurrence in the suture group (Figs. 2, 3). However, the rate of recurrent herniation did not differ significantly between the groups $(\mathrm{P}=0.580)$.

\section{Discussion}

Lumbar discectomy is widely performed for the treatment of lumbar HIVD and has shown good results in $>80 \%$ of cases [12-14]. Nevertheless, the incidence of recurrent hernination after surgery has been reported to be as high as $15 \%[3,6,15]$. Lebow et al. [16] reported that one-fourth of patients who underwent discectomy suffered from recurrent herniation at the same level within 2 years. According to the Spine Patient Outcomes Research Trial, the recurrence rate within 8 years after discectomy was $9.1 \%$, of which $37.8 \%$ recurred within 1 year after surgery [17]. Recurrent herniation has been reported to be related to the amount of nucleus pulposus removed during surgery and the posterior structure of the damaged vertebra. Specifically, it has been reported that recurrence is more common when the annular tear is $>6 \mathrm{~mm}[15,18,19]$. Since healing of the annulus is limited, the recurrence rate is
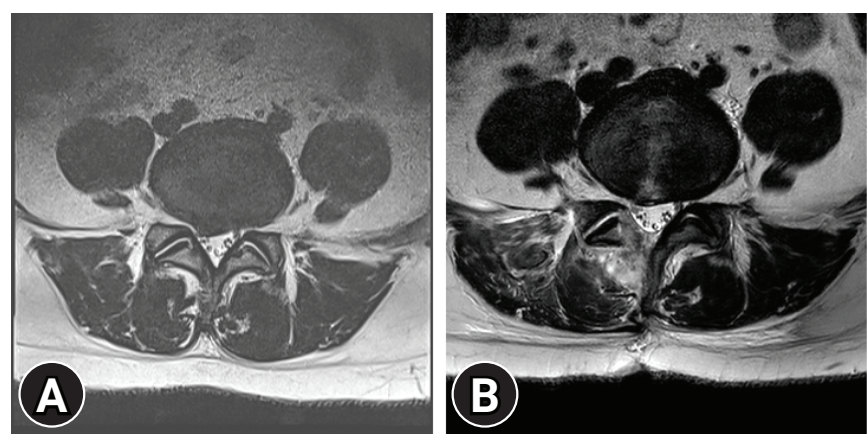

Fig. 2. A 23-year-old female presented with radiating pain in the right lower extremity. (A) Preoperative magnetic resonance imaging (MRI) showed right centrally herniated intervertebral disc at the $L 4 / 5$ level. She underwent microscopic discectomy with annuloplasty. (B) MRI at postoperative 1 month showed no evidence of recurrent herniation. Written informed consent was obtained for publication of this case report and accompanying images.

thought to be higher in patients with severe annulus tears or those who have undergone annulotomy. Owing to the limitations of healing, the need for annular repair has increased. This study was conducted based on the hypothesis that annular repair would be effective in increasing the healing potential of the annulus, securing vertebral stability, and reducing the recurrence rate and pain. It is noteworthy that there was no case of recurrent herniation in the suture group, whereas the rate of recurrence was $5.0 \%$ in the non-suture group. Although the difference was not statistically significant due to the relatively small number of patients, annuloplasty seemed to play a role in preventing recurrent herniation.

Two methods of annular repair have been reported: direct suturing or using a closure device $[7,20]$. In this study, we directly performed a traditional simple suture. This method requires a suffi- 

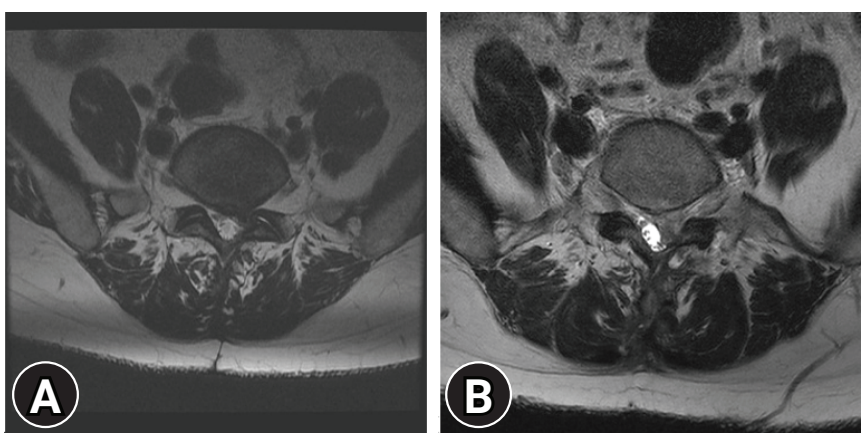

Fig. 3. A 44-year-old female presented with radiating pain and weakness in the left lower extremity. (A) Preoperative magnetic resonance imaging (MRI) showed left centrally herniated intervertebral disc at L5/S1 level. She underwent microscopic discectomy without annuloplasty. (B) She complained of recurrent radiating pain in the left lower extremity at 3 months after surgery. Follow-up MRI demonstrated recurrent herniation. Her symptom improved after revision surgery. Written informed consent was obtained for publication of this case report and accompanying images.

cient operative field combined with extended laminectomy, and surgeon's skill to make a suture in a narrow space. In the present study, the mean operation time in the suture group (66.82 \pm 13.01 minutes) was not significantly longer than that in the non-suture group (63.14 \pm 20.54 minutes; $\mathrm{P}=0.305)$. The mean EBL did not differ between groups. On the other hand, the length of hospital stay in the suture group ( $7.91 \pm 0.92$ days) was significantly shorter than that in the non-suture group $(11.35 \pm 4.10 ; \mathrm{P}=0.002)$. Furthermore, the postoperative VAS score in the suture group $(0.36 \pm 0.49)$ was significantly lower than that in the non-suture group $(0.74 \pm 0.77 ; \mathrm{P}=0.006)$. These results suggest that annular repair performed by a skilled surgeon could result in better clinical outcomes without a significant increase in the operation time.

This study had several limitations. The first limitation was the retrospective design, without randomization. Because the annular repair was determined by the surgeon's preference, the study was prone to selection bias. Second, the number of patients in each group was relatively small. Therefore, there were significant differences regarding baseline characteristics between the groups, including the mean age and symptom duration. Also, the small number of patients may explain why the difference in recurrent herniation between the groups was not statistically significant. Third, the follow-up period was shorter than that in the other studies. Therefore, this study could not evaluate recurrence at $>6$ months postoperatively [16]. Lastly, we did not evaluate the other possible risk factors that may affect recurrent herniation including comorbidities, smoking, detailed surgical findings, and radiographic characteristics. Of particular importance, the amount of disc removed during surgery or the disc height before and after surgery were not evaluated. It is necessary to perform future analysis of risk factors utilizing multivariate regression analysis to verify the benefit of the annuloplasty. Despite these limitations, the absence of recurrent herniation in the suture group supports the hypothesis that annular repair helps annular healing and reduces the recurrence rate. In order to further support this hypothesis, it is necessary to conduct a prospective study in which patients' risk factors for recurrence were evaluated in multiple ways and strictly controlled variables.

\section{Conclusion}

There were no cases of recurrent herniation in the suture group, whereas the rate of recurrence was $5.0 \%$ in the non-suture group. Although the difference was not statistically significant, annuloplasty may be considered as a simple method to prevent recurrent herniation. Further studies including larger number of patients and longer follow-up periods are required to verify the effectiveness of annular repair.

\section{Conflicts of interest}

No potential conflict of interest relevant to this article was reported.

\section{ORCID}

Taewon Choi, https://orcid.org/0000-0001-7914-3095

Ho Yong Choi, https://orcid.org/0000-0002-5545-4283

Dae Jean Jo, https://orcid.org/0000-0003-3304-3931

\section{REFERENCES}

1. Davis RA. A long-term outcome analysis of 984 surgically treated herniated lumbar discs.J Neurosurg 1994;80:415-21.

2. Gray DT, Deyo RA, Kreuter W, et al. Population-based trends in volumes and rates of ambulatory lumbar spine surgery. Spine (Phila Pa 1976) 2006;31:1957-64.

3. Swartz KR, Trost GR. Recurrent lumbar disc herniation. Neurosurg Focus 2003;15:E10.

4. Häkkinen A, Kiviranta I, Neva MH, Kautiainen H, Ylinen J. Reoperations after first lumbar disc herniation surgery; a special interest on residives during a 5-year follow-up. BMC Musculoskelet Disord 2007;8:2.

5. McGirt MJ, Ambrossi GL, Datoo G, et al. Recurrent disc herniation and long-term back pain after primary lumbar discectomy: review of outcomes reported for limited versus aggressive disc 
removal. Neurosurgery 2009;64:338-45.

6. Bron JL, Helder MN, Meisel HJ, Van Royen BJ, Smit TH. Repair, regenerative and supportive therapies of the annulus fibrosus: achievements and challenges. Eur Spine J 2009; 18:301-13.

7. Qi L, Li M, Si H, et al. The clinical application of "jetting suture" technique in annular repair under microendoscopic discectomy: a prospective single-cohort observational study. Medicine (Baltimore) 2016;95:e4503.

8. Vukas D, Ledić D, Grahovac G, Kolić Z, Rotim K, Vilendecić M. Clinical outcomes in patients after lumbar disk surgery with annular reinforcement device: two-year follow up. Acta Clin Croat 2013;52:87-91.

9. Thomé C, Klassen PD, Bouma GJ, et al. Annular closure in lumbar microdiscectomy for prevention of reherniation: a randomized clinical trial. Spine J 2018;18:2278-87.

10. Klassen PD, Bernstein DT, Köhler HP, et al. Bone-anchored annular closure following lumbar discectomy reduces risk of complications and reoperations within 90 days of discharge. J Pain Res 2017;10:2047-55.

11. Ardeshiri A, Miller LE, Thomé C. Two-year real-world results of lumbar discectomy with bone-anchored annular closure in patients at high risk of reherniation. Eur Spine J 2019;28:2572-8.

12. Buttermann GR. Treatment of lumbar disc herniation: epidural steroid injection compared with discectomy: a prospective, randomized study.J Bone Joint Surg Am 2004;86:670-9.

13. Asch HL, Lewis PJ, Moreland DB, et al. Prospective multiple outcomes study of outpatient lumbar microdiscectomy: should 75 to $80 \%$ success rates be the norm? J Neurosurg 2002;96(1
Suppl):34-44.

14. Dewing CB, Provencher MT, Riffenburgh RH, Kerr S, Manos RE. The outcomes of lumbar microdiscectomy in a young, active population: correlation by herniation type and level. Spine (Phila Pa 1976) 2008;33:33-8.

15. Carragee EJ, Han MY, Suen PW, Kim D. Clinical outcomes after lumbar discectomy for sciatica: the effects of fragment type and anular competence. J Bone Joint Surg Am 2003;85:102-8.

16. Lebow RL, Adogwa O, Parker SL, Sharma A, Cheng J, McGirt MJ. Asymptomatic same-site recurrent disc herniation after lumbar discectomy: results of a prospective longitudinal study with 2-year serial imaging. Spine (Phila Pa 1976) 2011;36:2147-51.

17. Abdu RW, Abdu WA, Pearson AM, Zhao W, Lurie JD, Weinstein JN. Reoperation for recurrent intervertebral disc herniation in the spine patient outcomes research trial: analysis of rate, risk factors, and outcome. Spine (Phila Pa 1976) 2017;42:1106-14.

18. Gotfried Y, Bradford DS, Oegema TR Jr. Facet joint changes after chemonucleolysis-induced disc space narrowing. Spine (Phila Pa 1976) 1986;11:944-50.

19. Chiang YF, Chiang CJ, Yang CH, et al. Retaining intradiscal pressure after annulotomy by different annular suture techniques, and their biomechanical evaluations. Clin Biomech (Bristol, Avon) 2012;27:241-8.

20. Bateman AH, Balkovec C, Akens MK, et al. Closure of the annulus fibrosus of the intervertebral disc using a novel suture application device: in vivo porcine and ex vivo biomechanical evaluation. Spine J 2016;16:889-95. 